\title{
Associations between DNA methylation and BMI vary by metabolic health status: a potential link to disparate cardiovascular outcomes
}

Whitney L. Do ${ }^{1^{*}}$ (i), Steve Nguyen ${ }^{2}$, Jie Yao ${ }^{3}$, Xiuqing Guo ${ }^{3}$, Eric A. Whitsel ${ }^{4}$, Ellen Demerath ${ }^{5}$, Jerome I. Rotter ${ }^{3}$, Stephen S. Rich ${ }^{6}$, Leslie Lange ${ }^{7}$, Jingzhong Ding ${ }^{8}$, David Van Den Berg ${ }^{9}$, Yongmei Liu ${ }^{10}$, Anne E. Justice ${ }^{11}$, Weihua Guan ${ }^{12}$, Steve Horvath ${ }^{13}$, Themistocles L. Assimes ${ }^{14}$, Parveen Bhatti ${ }^{15}$, Kristina Jordahl ${ }^{16}$, Aladdin Shadyab ${ }^{2}$, Celina I. Valencia ${ }^{17}$, Aryeh D. Stein ${ }^{18}$, Alicia Smith ${ }^{19}$, Lisa R. Staimez ${ }^{18}$, Karen Conneely ${ }^{20}$ and K. M. Venkat Narayan ${ }^{18}$

\begin{abstract}
Background: Body mass index (BMI), a well-known risk factor for poor cardiovascular outcomes, is associated with differential DNA methylation (DNAm). Similarly, metabolic health has also been associated with changes in DNAm. It is unclear how overall metabolic health outside of BMI may modify the relationship between BMI and methylation profiles, and what consequences this may have on downstream cardiovascular disease. The purpose of this study was to identify cytosine-phosphate-guanine $(\mathrm{CpG})$ sites at which the association between BMI and DNAm could be modified by overall metabolic health.

Results: The discovery study population was derived from three Women's Health Initiative (WHI) ancillary studies $(n=3977)$ and two Atherosclerosis Risk in Communities (ARIC) ancillary studies $(n=3520)$. Findings were validated in the Multi-Ethnic Study of Atherosclerosis (MESA) cohort $(n=1200)$. Generalized linear models regressed methylation $\beta$ values on the interaction between $\mathrm{BMI}$ and metabolic health $Z$ score $(\mathrm{BMI} \times \mathrm{MHZ}$ ) adjusted for BMI, $\mathrm{MHZ}$, cell composition, chip number and location, study characteristics, top three ancestry principal components, smoking, age, ethnicity (WHI), and sex (ARIC). Among the 429,566 sites examined, differential associations between $\mathrm{BMI} \times \mathrm{MHZ}$ and DNAm were identified at $22 \mathrm{CpG}$ sites (FDR $q<0.05$ ), with one site replicated in MESA (cg18989722, in the TRAPPC9 gene). Three of the 22 sites were associated with incident coronary heart disease (CHD) in WHI. For each 0.01 unit increase in DNAm $\beta$ value, the risk of incident CHD increased by $9 \%$ in one site and decreased by $6-10 \%$ in two sites over 25 years.
\end{abstract}

Conclusions: Differential associations between DNAm and BMI by MHZ were identified at 22 sites, one of which was validated (cg18989722) and three of which were predictive of incident CHD. These sites are located in several genes related to NF-kappa-B signaling, suggesting a potential role for inflammation between DNA methylation and BMIassociated metabolic health.

*Correspondence: Iwhitney16@gmail.com

${ }^{1}$ Nutrition and Health Sciences Program, Laney Graduate School, Emory

University, 1518 Clifton Rd, Atlanta, GA 30322, USA

Full list of author information is available at the end of the article original author(s) and the source, provide a link to the Creative Commons licence, and indicate if changes were made. The images or other third party material in this article are included in the article's Creative Commons licence, unless indicated otherwise in a credit line to the material. If material is not included in the article's Creative Commons licence and your intended use is not permitted by statutory regulation or exceeds the permitted use, you will need to obtain permission directly from the copyright holder. To view a copy of this licence, visit http://creativecommons.org/licenses/by/4.0/. The Creative Commons Public Domain Dedication waiver (http://creativeco mmons.org/publicdomain/zero/1.0/) applies to the data made available in this article, unless otherwise stated in a credit line to the data. 
Keywords: DNA methylation, Metabolically healthy, Obesity, Epigenetics

\section{Background}

Obesity rates continue to rise with obesity occurring in more than $41.1 \%$ of women in the USA in 2016 [1]. While obesity is most typically defined as body mass index (BMI) $>30 \mathrm{~kg} / \mathrm{m}^{2}$, limitations in the use of BMI have been noted, including variation in associations with health outcomes by race/ancestry, physical activity, and age [2, $3]$, as well as some reports finding no association between higher-risk categories (overweight and middle obesity) with mortality $[4,5]$. These conflicting reports have motivated several studies to examine whether differential phenotypes of obesity exist and whether examining BMI in isolation of additional metabolic health parameters is a sufficient metric of overall health.

A growing body of evidence has found heterogeneity in obesity, with some phenotypes exhibiting differential risk for cardiovascular outcomes. Metabolically healthy obesity (MHO) has been defined as obesity with less than two or three metabolic health risk factors. Some but not all studies have found MHO to be associated with reduced risk of cardiovascular outcomes compared to metabolically unhealthy obesity (MUO) [6-11]. In a recent systematic review, MHO had a higher risk of cardiovascular events than metabolically healthy, normal weight participants (risk ratio [RR] 1.45 , 95\% CI 1.20-1.70, reference metabolically healthy, normal weight), but had lower risk to metabolically unhealthy normal weight (RR 2.07, 95\% CI 1.62-2.65, reference metabolically healthy, normal weight) and MUO individuals (RR 2.31, 95\% CI 1.99-2.69, reference metabolically healthy, normal weight) [12]. These findings suggest that metabolic health status may differentially influence the relationship between BMI and health outcomes. Examining the molecular underpinnings of this phenotype may guide our understanding of this epidemiological phenomenon by identifying the biological mechanisms which may be leading to a reduction in risk of health outcomes associated with obesity. Additionally, identifying biomarkers of MHO, particularly if they can identify individuals more likely to remain in $\mathrm{MHO}$, would be advantageous for more targeted interventions.

Epigenetic mechanisms, such as DNA methylation (DNAm), are important biological features to examine in the context of chronic diseases such as obesity and metabolic health. Changes to DNAm can induce changes in gene expression in causal disease pathways potentially mediating or modifying differential health outcomes [13]. Obesity has been widely examined and shown to associate with prolific methylation changes in the blood and adipose tissue [14-16]. Similarly, metabolic syndrome and metabolic health risk factors have been found to associate with differential methylation [17-21]. Indeed the mouse model which is used to represent $\mathrm{MHO}$ is developed from deletion of the BRD2 gene, which is a primary epigenetic regulator of histone acetylation [22]. However, no studies have integrated these phenotypes to examine how BMI-associated methylation varies by metabolic health status. Particularly since DNAm has been reported to mediate the relationship between obesity and increased cardiovascular outcomes [23], evaluating the epigenome may provide insight into pathways contributing to the differences in outcomes. Thus, the purpose of this study is to examine whether BMI associates with methylation differentially according to metabolic health status (Fig. 1).

\section{Results}

A summary of the methods is included in Fig. 2.

Metabolically healthy obesity:

- High BMI

- Normal glucose

- Normal blood pressure

- Normal blood lipids

- Normal waist circumference

Metabolically unhealthy obesity:

- High BMI

- High glucose

- High blood pressure

- High blood lipids

- High waist circumference

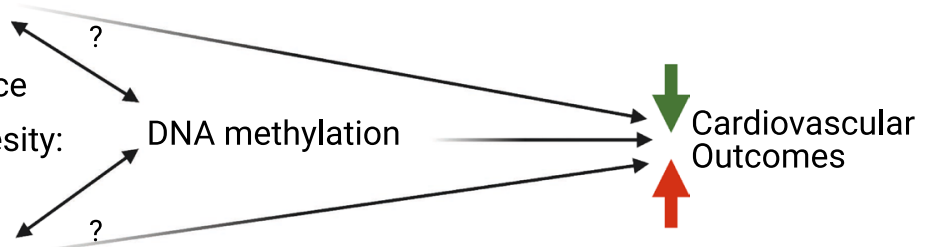

Created with BioRender.com

Fig. 1 Conceptual framework research question. Abbreviations: BMI, body mass index 


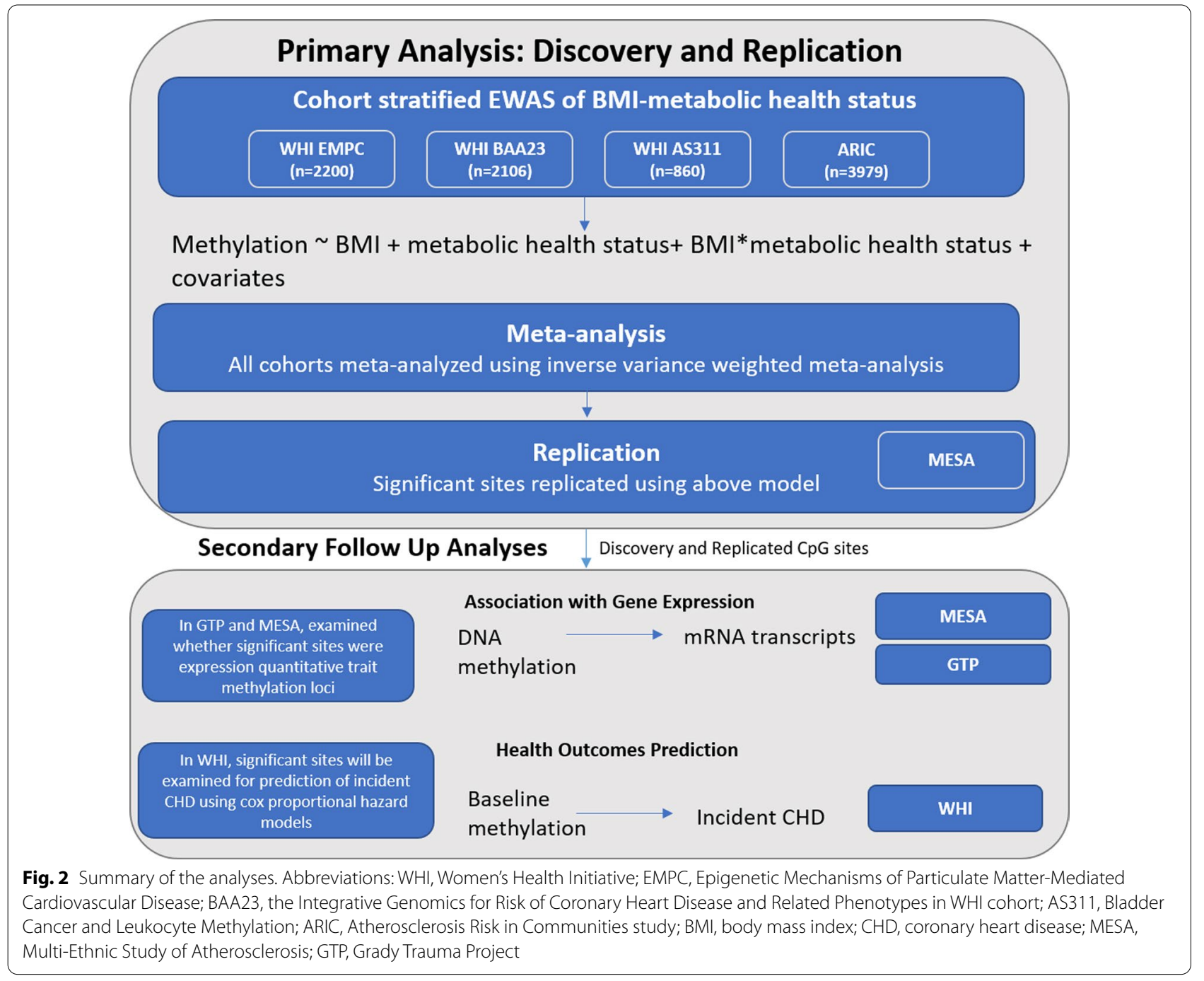

Demographic characteristics of the cohorts are described in Table 1 for the three ancillary studies from the Women's Health Initiative (WHI) including Epigenetic Mechanisms of Particulate Matter-Mediated Cardiovascular Disease (EMPC, aka AS315), the Integrative Genomics for Risk of Coronary Heart Disease and Related Phenotypes in WHI cohort (BAA23), and Bladder Cancer and Leukocyte Methylation (AS311) and the two ancillary studies from the Atherosclerosis Risk in Communities study (ARIC) including European Americans (EA) and African Americans (AA). Overall, 7497 participants were included in the discovery analysis. To examine the differential impact of metabolic health status on $\mathrm{BMI}$, linear regression models were used regressing the methylation $\beta$ value on the interaction term for BMI and metabolic health status, adjusting for each higherlevel variable (BMI and metabolic health) and covariates.
We conducted two epigenome-wide assocation study (EWAS) with metabolic health status defined dichotomously $(\mathrm{BMI} \times \mathrm{MH})$ and continuously $(\mathrm{BMI} \mathrm{x}$ metabolic health Z-score [MHZ]). We identified no statistically significant differential associations between cytosine and guanine nucleotide pair (CpG) methylation and BMI by dichotomized metabolic health status (BMIxMH). When metabolic health status was examined continuously (MHZ), 22 CpG sites were associated with BMIxMHZ (false discovery rate [FDR] $q$ value $<0.05$, Table 2; Fig. 3 ). For ease of interpretation, we described the direction of effect in the 22 significant sites in the models examining BMI $\times$ MH (Additional file 1: Table S1). In 13 of the 22 sites, an increase in BMI was associated with an opposite direction of effect in the coefficient in metabolically healthy vs unhealthy individuals. In the replication analysis in the Multi-Ethnic Study of Atherosclerosis (MESA), 
Table 1 Demographic characteristics of each ancillary study in the Women's Health Initiative (WHI) and the Atherosclerosis Risk in Communities (ARIC)

ARIC AA $(n=2461)$

\begin{tabular}{|c|c|c|c|c|c|}
\hline \multicolumn{6}{|l|}{ Clinical trial participant } \\
\hline Yes & 1833 & 1543 & 119 & - & - \\
\hline No & 0 & 434 & 48 & - & - \\
\hline \multicolumn{6}{|l|}{ Case/control status } \\
\hline Case & - & 987 & 91 & - & - \\
\hline Control & - & 990 & 76 & - & - \\
\hline Age mean (SD) & $63.2(7.1)$ & $64.6(7.1)$ & $66.2(7.2)$ & $59.9(5.4)$ & $56.6(5.9)$ \\
\hline \multicolumn{6}{|l|}{ Sex } \\
\hline Female & 1833 & 1977 & 167 & 611 & 1574 \\
\hline Male & 0 & 0 & 0 & 448 & 887 \\
\hline \multicolumn{6}{|l|}{ Ethnicity } \\
\hline White & 922 & 944 & 99 & 1059 & 0 \\
\hline African American & 474 & 631 & 49 & 0 & 2461 \\
\hline Hispanic/Latino & 260 & 402 & 16 & 0 & 0 \\
\hline Asian or Pacific Islander & 107 & 0 & 2 & 0 & 0 \\
\hline American Indian or Alaskan Native & 41 & 0 & 1 & 0 & 0 \\
\hline Other & 29 & 0 & 0 & 0 & 0 \\
\hline \multicolumn{6}{|l|}{ Smoking status } \\
\hline Former and current & 853 & 913 & 99 & 610 & 1351 \\
\hline Never & 963 & 1048 & 67 & 449 & 1110 \\
\hline \multicolumn{6}{|l|}{ Metabolic health status } \\
\hline Metabolically healthy & 1254 & 1163 & 109 & 662 & 1177 \\
\hline Metabolically unhealthy & 579 & 814 & 58 & 397 & 1284 \\
\hline BMI*Metabolic Health Z score mean (SD) & $2.96(30.38)$ & $2.92(31.59)$ & $2.84(30.4)$ & $2.55(29.0)$ & $2.82(31.4)$ \\
\hline BMI mean (SD) & $29.5(5.9)$ & $29.8(6.1)$ & $29.3(6.9)$ & $26.2(4.3)$ & $30.1(6.2)$ \\
\hline \multicolumn{6}{|l|}{ BMI categories } \\
\hline Underweight & 7 & 13 & 0 & 20 & 18 \\
\hline Normal & 417 & 420 & 41 & 435 & 444 \\
\hline Overweight & 641 & 680 & 67 & 429 & 912 \\
\hline Obese & 768 & 864 & 59 & 175 & 1087 \\
\hline Waist circumference mean (SD) & $89.5(13.8)$ & $90.7(13.7)$ & $89.1(15.1)$ & $94.5(12.8)$ & $101.4(15.1)$ \\
\hline Triglycerides mean (SD) & $153(88.2)$ & $146.9(83.4)$ & $143.8(82.5)$ & $140.4(83.6)$ & $117.3(77.7)$ \\
\hline HDL-cholesterol mean (SD) & $58(15.1)$ & $52.1(13.2)$ & $53.2(13.0)$ & $52.3(18.2)$ & $53.3(17.3)$ \\
\hline Systolic blood pressure mean (SD) & $128(18)$ & $132.1(17.8)$ & $132.5(16.6)$ & $118.7(18.0)$ & $127.3(20.6)$ \\
\hline Diastolic Blood Pressure mean (SD) & $75.3(9.4)$ & $76.4(9.3)$ & $76.3(8.5)$ & $68.5(9.7)$ & $75.2(10.7)$ \\
\hline Blood glucose mean (SD) & $103(31.1)$ & $108.6(41.3)$ & $105.2(37.2)$ & $105.9(28.6)$ & $129.3(64.3)$ \\
\hline
\end{tabular}

Means [standard deviation (SD)] or proportions have been included

EMPC, epigenetic mechanisms of particulate matter-mediated cardiovascular disease; BAA23, the integrative genomics for risk of coronary heart disease and related phenotypes in WHI cohort; AS311, bladder cancer and leukocyte methylation; BMI, Body Mass Index; EA, European American; AA, African American

cg18989722 associated with BMIxMHZ $(p<0.05$ in a consistent direction, Additional file 1: Table S2). cg18989722 inversely associated with $\mathrm{BMI} \times \mathrm{MHZ}$. When examining $\mathrm{BMI} \times \mathrm{MH}$ in this site, every unit increase in $\mathrm{BMI}$ was associated with increased DNAm in metabolically healthy individuals and decreased methylation in metabolically unhealthy individuals. We examined a gene ontology analysis of the 22 significant sites. However, no pathways were significantly enriched.

Given the known relationships between obesity and metabolic status and cardiovascular disease, we examined whether DNAm taken at baseline predicted incident myocardial infarction over 25 years in the WHI. After excluding individuals from WHI with a history of cardiovascular disease, 3746 individuals remained (BAA23 
Table 2 Significant sites associated with body mass index * metabolic health Z score interaction (BMIxMHZ) including the effect size for the higher-level variables

\begin{tabular}{|c|c|c|c|c|c|c|c|c|}
\hline CpG site & $\begin{array}{l}\text { Effect size } \\
(\mathrm{BMI} \times \mathrm{MHZ})\end{array}$ & Standard error & $Z$ score & $P$ value & FDR $q$ value & Direction & $\begin{array}{l}\text { Effect size } \\
\text { (BMI) }\end{array}$ & $\begin{array}{l}\text { Effect size } \\
\text { (MHZ) }\end{array}$ \\
\hline cg24827562 & $-8.71 \mathrm{E}-05$ & $9.83 \mathrm{E}-06$ & $-8.41 \mathrm{E}+00$ & $3.98 \mathrm{E}-17$ & $1.70 \mathrm{E}-11$ & -+++- & $9.27 \mathrm{E}-06$ & 0.00161952 \\
\hline cg02851049 & $-8.85 E-05$ & $1.04 \mathrm{E}-05$ & $-7.91 \mathrm{E}+00$ & $2.53 E-15$ & $5.39 E-10$ & ++-+- & $-8.49 E-06$ & 0.00126491 \\
\hline cg22076143 & $-1.01 \mathrm{E}-04$ & $1.27 \mathrm{E}-05$ & $-7.62 E+00$ & $2.55 E-14$ & $3.63 \mathrm{E}-09$ & -+++- & $-1.47 \mathrm{E}-06$ & 0.00119747 \\
\hline cg20210586 & $-1.03 E-04$ & $1.39 E-05$ & $-6.97 E+00$ & $3.28 \mathrm{E}-12$ & $3.49 \mathrm{E}-07$ & --++- & $1.38 \mathrm{E}-05$ & 0.00237264 \\
\hline $\operatorname{cg} 18989722$ & $-8.36 \mathrm{E}-05$ & $1.20 \mathrm{E}-05$ & $-6.54 \mathrm{E}+00$ & $6.14 \mathrm{E}-11$ & $4.86 \mathrm{E}-06$ & -+-+- & $-5.73 \mathrm{E}-06$ & 0.00139622 \\
\hline cg15062225 & $-1.38 \mathrm{E}-04$ & $2.05 E-05$ & $-6.52 E+00$ & $6.83 \mathrm{E}-11$ & $4.86 \mathrm{E}-06$ & -+-+- & $8.86 \mathrm{E}-05$ & 0.00309348 \\
\hline cg24460625 & $-7.26 \mathrm{E}-05$ & $1.11 \mathrm{E}-05$ & $-6.38 \mathrm{E}+00$ & $1.80 \mathrm{E}-10$ & $1.10 \mathrm{E}-05$ & -+-+- & $2.29 E-06$ & 0.00186604 \\
\hline $\operatorname{cg} 10057841$ & $-9.86 \mathrm{E}-05$ & $1.56 \mathrm{E}-05$ & $-5.99 E+00$ & $2.04 \mathrm{E}-09$ & $1.09 \mathrm{E}-04$ & ---+- & $3.25 \mathrm{E}-05$ & 0.0020491 \\
\hline cg06344952 & $-9.11 \mathrm{E}-05$ & $1.46 \mathrm{E}-05$ & $-5.79 E+00$ & $7.23 \mathrm{E}-09$ & $3.43 \mathrm{E}-04$ & ---+- & $5.91 \mathrm{E}-05$ & 0.00307032 \\
\hline cg26206680 & $-6.13 E-05$ & $9.90 \mathrm{E}-06$ & $-5.73 E+00$ & $9.98 \mathrm{E}-09$ & $4.26 \mathrm{E}-04$ & ++-+- & $-7.74 \mathrm{E}-06$ & 0.00014127 \\
\hline cg27004639 & $5.20 \mathrm{E}-05$ & $9.14 \mathrm{E}-06$ & $5.64 \mathrm{E}+00$ & $1.66 \mathrm{E}-08$ & $6.34 \mathrm{E}-04$ & +-+-+ & $4.21 \mathrm{E}-05$ & -0.0017364 \\
\hline cg19572849 & $-4.99 E-05$ & $8.96 \mathrm{E}-06$ & $-5.63 E+00$ & $1.78 \mathrm{E}-08$ & $6.34 \mathrm{E}-04$ & -+++- & $-1.67 \mathrm{E}-05$ & 0.00155317 \\
\hline cg08082299 & $-1.01 \mathrm{E}-04$ & $1.73 E-05$ & $-5.59 \mathrm{E}+00$ & $2.25 \mathrm{E}-08$ & $7.37 \mathrm{E}-04$ & -+++- & $-1.49 \mathrm{E}-05$ & 0.00209263 \\
\hline cg18298785 & $-8.52 \mathrm{E}-05$ & $1.40 \mathrm{E}-05$ & $-5.58 \mathrm{E}+00$ & $2.42 \mathrm{E}-08$ & 7.37E-04 & -+++- & $-2.99 \mathrm{E}-07$ & 0.00212176 \\
\hline $\operatorname{cg} 16543390$ & $6.71 \mathrm{E}-05$ & $1.38 \mathrm{E}-05$ & $5.26 \mathrm{E}+00$ & $1.46 \mathrm{E}-07$ & $4.16 \mathrm{E}-03$ & -+-++ & $3.05 E-05$ & -0.0022199 \\
\hline $\operatorname{cg} 16461485$ & $-1.15 E-04$ & $2.06 \mathrm{E}-05$ & $-5.23 E+00$ & $1.71 \mathrm{E}-07$ & $4.34 \mathrm{E}-03$ & -+-+- & 8.27E-05 & 0.00151377 \\
\hline cg21880445 & $-7.90 \mathrm{E}-05$ & $1.44 \mathrm{E}-05$ & $-5.23 E+00$ & $1.73 \mathrm{E}-07$ & $4.34 \mathrm{E}-03$ & -+++- & $-3.03 E-05$ & 0.00174726 \\
\hline cg07226317 & $-9.17 E-05$ & $1.62 \mathrm{E}-05$ & $-5.16 E+00$ & $2.53 \mathrm{E}-07$ & $6.00 E-03$ & -+-+- & $3.12 \mathrm{E}-05$ & 0.00135378 \\
\hline cg05441596 & $-5.74 \mathrm{E}-05$ & $1.11 \mathrm{E}-05$ & $-4.95 E+00$ & $7.39 \mathrm{E}-07$ & $1.62 \mathrm{E}-02$ & ++++- & $3.48 \mathrm{E}-05$ & 0.00106747 \\
\hline cg24720717 & $6.22 \mathrm{E}-05$ & $1.22 \mathrm{E}-05$ & $4.95 E+00$ & $7.59 \mathrm{E}-07$ & $1.62 \mathrm{E}-02$ & ++--+ & $-7.25 \mathrm{E}-06$ & -0.002551 \\
\hline cg11553983 & $-6.96 \mathrm{E}-05$ & $1.36 \mathrm{E}-05$ & $-4.76 \mathrm{E}+00$ & $1.94 \mathrm{E}-06$ & $3.88 \mathrm{E}-02$ & +--+- & $3.50 \mathrm{E}-05$ & 0.00075824 \\
\hline cg00868074 & $3.15 \mathrm{E}-04$ & $6.90 E-05$ & $4.75 E+00$ & $2.00 \mathrm{E}-06$ & $3.88 \mathrm{E}-02$ & +++++ & -0.0003756 & -0.0140558 \\
\hline
\end{tabular}

Direction of effect has been included for the individual ancillary studies from the WHI, Women's Health Initiative; EMPC, epigenetic mechanisms of particulate mattermediated cardiovascular disease; BAA23, the integrative genomics for risk of coronary heart disease and related phenotypes in WHI cohort; AS311, bladder cancer and leukocyte methylation; ARIC, the Atherosclerosis Risk in Communities Study; EA, European American; AA, African American, respectively

$n=1823$, EMPC $n=1775$, AS311 $n=148)$. In WHI, there were 714 events (number of events $=585$ [BAA23], 113 [EMPC], 16 [AS311]) with an average follow up of 14-15 years (mean follow up = BAA23 14.0 years, EMPC 15.69 years, AS311 15.85 years). When predicting incident coronary heart disease (CHD), we initially examined whether the interaction between $\mathrm{BMI} \times \mathrm{MHZ}$ taken at baseline was associated with incident $\mathrm{CHD}$, adjusting for BMI, MHZ, case-control status, age, smoking status, and ethnicity. BMIxMHZ was significantly associated with incident CHD (hazard ratio [HR] 1.02, 95\% CI 1.004, $1.03, p$ value $=0.005$, Fig. $4 \mathrm{~A}$ ). Then we added the DNA methylation at $\operatorname{cg} 18989722$ as a predictor and found that it was not associated with incident CHD (Additional file 1: Table S3). However, when examining the 22 sites from the discovery analysis, three sites were associated with incident $\mathrm{CHD}$ adjusted for the reduced set of covariates $(p<0.05$, Fig. $4 \mathrm{~B}-\mathrm{D}$; Table 3$)$. In models adjusting for the full set of covariates, two sites were significantly associated with CHD, cg16461485 and cg16543390.

For the replicated site and the three sites associated with incident CHD in the reduced set of covariates, we examined whether they were associated with differential gene expression in the blood in two cohorts: Grady Trauma Project (GTP) and MESA (Additional file 1: Table S4). None of the sites were reported to be associated with gene expression in cis. cg18989722 (in chromosome 8) was associated with differential expression of PTGS1 in chromosome 9 and cg16461485 (in chromosome 3) was associated with differential expression of TNFRSF13B in chromosome 17 representing trans associations.

In sensitivity analyses, we examined the change in the association of $\mathrm{BMI} \times \mathrm{MHZ}$ with the 22 significant $\mathrm{CpG}$ sites in the WHI and ARIC when adjusted for physical activity. After including physical activity as a covariate, $\mathrm{BMI} \times \mathrm{MHZ}$ was no longer significantly associated with any CpG site. However, this may be in part due to a reduction in power as the effect sizes did not change significantly in the significant sites (correlation in effect sizes from main analysis compared to analysis adjusted for physical activity $=0.92$ ). When examining the change in the effect size when sequentially leaving out each of the metabolic health parameters one at a time from the 
MHZ score, omission of high-density lipoprotein cholesterol (HDL) most potently attenuated the effect estimate (effect estimate correlation $=0.89$, Additional file 1: Table S5). In the 22 sites, effect sizes and $Z$ scores changed minimally when adjusted for lipid, hypertension, and glycemic medications (all correlations in effect size $=0.97$ and all correlations in $Z$ scores $=0.95$ ). We examined the influence of individual ancillary studies on the results by examining the change in significance and effect size when ancillary studies (BAA23, EMPC, AS311, ARIC AA, and ARIC EA) were individually excluded from the analysis. Significance changed moderately with exclusion of each study with $30,20,25,20$ and 27 significant sites when BAA23, EMPC, AS311, ARIC AA, and ARIC EA were excluded, respectively. Differences in effect size were minor (correlation with main analysis $=0.99)$ in all studies except with exclusion of ARIC AA (correlation with main analysis $=0.86$, Additional file 1: Figures S1-S5). We additionally examined the residuals of the four sites described above in the EWAS models to assess violations of a non-normal distribution (Additional file 1: Figures S6-S13). These plots appear to be consistent with a normal distribution, with the exception of ARIC EA. When ARIC EA is excluded from the analysis, all 22 remain significant and $Z$ scores tend to be higher as compared to the full analysis.

\section{Discussion}

In this study, we found $22 \mathrm{CpG}$ sites were associated with BMIxMHZ in the WHI and ARIC cohorts, with one site replicating in a consistent direction in MESA. Among the 22 sites, two CpG sites inversely and one CpG site positively associated with a change in incidence of $\mathrm{CHD}$ over 25 years in the WHI cohort.

One site replicated in MESA in a consistent direction, cg18989722 located in the body of the TRAPPC9 gene. TRAPPC9 has been shown to play a role in NF-kappa-B signaling by activating NF-kappa-B through increased phosphorylation of the IKK complex [24]. TRAPPC9 encodes NIBP, which binds to IKK/NIK to enhance NFkappa-B activation. TRAPPC9 has recently been identified as an imprinted gene primarily expressing the maternal allele (70\% of transcripts in the brain expressed maternal allele). TRAPPC9 knock-out mice exhibit a rare intellectual disability accompanied by an increase in fat mass and body weight [25], suggesting that expression of this gene may protect against obesity. Several CpG sites in TRAPPC9 have been identified in EWAS of childhood adiposity [26, 27]. As gene body methylation has often been cited as an indicator of an active gene [28], our findings are in alignment with previous reports of protection against obesity since individuals with lower BMIxMHZ had higher methylation in this site.
This site was also associated with increased gene expression of the PTGS1 gene. PTGS1 (also known as COX1) catalyzes the conversion of arachinodate to prostaglandin protein and is inhibited by anti-inflammatory drugs. In our sensitivity analysis, when adjusted for lipid medication use including peripheral vasodilators such as aspirin, the effect size moderately changed $\left(-8.36 \times 10^{-5}\right.$ in unadjusted models and $-5.25 \times 10^{-5}$ in adjusted models). However, the $Z$ score was smaller $(-6.54$ in unadjusted models and -2.55 in adjusted models). This suggests some attenuation in the relationship between $\mathrm{BMI} \times \mathrm{MHZ}$ and DNAm in this site is potentially modified by medication use.

Methylation in three sites was associated with incident CHD over 25 years in the WHI cohort: cg16461485 located in the body of SELT, cg02851049 located in the body of POLR3K, and $\operatorname{cg} 20210586$ in the body of TRIM39. None of these sites have been identified in previous EWAS. We also found that cg16461485 associated with reduced gene expression of TNFRSF13B, which encodes the tumor necrosis factor (TNF) receptor superfamily member $13 \mathrm{~B}$, also known as the transmembrane activator and CAML interactor (TACI). This protein activates NFAT, AP1, and NF-kappa-B [29]. TACI knockout mice were protected against high-fat-diet-induced inflammation and dysglycemia, which may be mediated by a shift in adipose tissue macrophages from M1 to M2, which tend to promote a phenotype of insulin sensitivity [30]. These findings further support the role that methylation in cg16461485 exhibiting a protective effect.

Given the molecular functions of these genes, differential inflammatory mechanisms (potentially mediated by the NF-kappa-B pathway) may account for the observed differences in health outcomes by BMIxMHZ. Obesity and several of the metabolic health parameters associate with excess inflammation [31]. However, some studies have posited that MHO may be due to an uncoupling of obesity and insulin resistance due to differential inflammatory mechanisms as $\mathrm{MHO}$ has been associated with lower inflammatory markers including $\mathrm{C}$-reactive protein (CRP), TNF- $\alpha$, interleukin-6 (IL-6), and plasminogen activator inhibitor-1 [32, 33]. As the CpG sites identified in this study were adjusted for cell composition which uses surrogate measures from six cell types [34], we may be identifying unique immune cell subsets associated with these disease exposures not captured by this method which may drive differences in outcomes. Additionally, several studies have also observed a unique relationship between inflammatory markers and adiposity in individuals of African descent, where these markers do not appear to be as sensitive to adiposity compared to individuals of European descent $[35,36]$. This may explain 


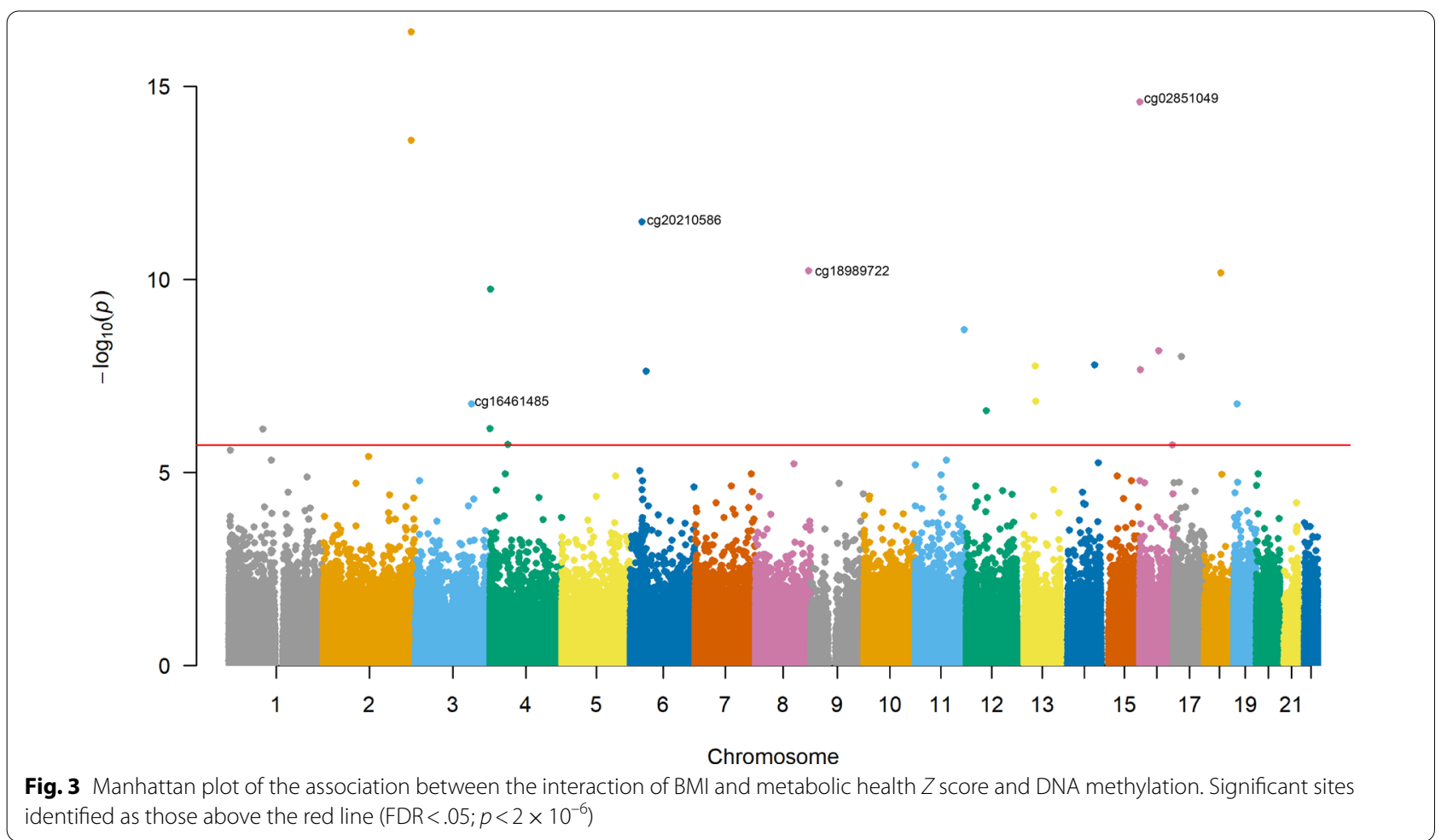

the significant differences observed when we exclude the ARIC AA cohort in sensitivity analyses.

When we adjusted for physical activity, no sites were significantly associated with $\mathrm{BMI} \times \mathrm{MHZ}$. We included this analysis as several studies have touted that MHO may be the product of increased fitness in this population $[36,37]$. This may be due to true confounding by physical activity. However, there may also be collinearity, as physical activity is highly associated with BMI $(p=2.5 \mathrm{e}-17)$ and metabolic health $(p=2.94 \mathrm{e}-12)$, which would lead to a reduction in significance in the identified variables. Future studies could further explore these associations in physical activity interventions in these populations.

There are several important limitations in this study. Given the cross-sectional design, we cannot determine any causal association and may be at risk of reverse causality, if methylation is contributing to changes in BMI or metabolic risk factors. Moreover, metabolic risk factors may also be a product of duration of obesity, since several studies have found $\mathrm{MHO}$ to be a transitory state $[6,7,37]$. However, understanding the methylomic differences in these populations would still be advantageous to identify biological mechanisms that may be driving the differences in outcomes. Another limitation includes the potential for confounding by cell composition. While we found unique relationships between three $\mathrm{CpG}$ sites and CHD, none of these sites replicated in an external population suggesting that other confounding factors may be causing this association. Nevertheless, the limited replication may be due in part to limited power as the replication analysis had the power to detect effect sizes as low as 0.01 and the effect sizes from our discovery EWAS were much lower (Additional file 1: Table S6). Additionally, the results may have diverged between ARIC and WHI populations since the WHI includes only women. While we adjusted for sex in ARIC, we may be identifying signals in WHI that are differential in women versus men. A strength of this study is examining the unique interaction between BMI and metabolic health in three population-based cohort studies and examining their impact on gene expression and CHD outcomes.

Overall, we found four $\mathrm{CpG}$ sites which may have a unique relationship with BMI in metabolically healthy vs unhealthy individuals. Our study findings may align with several studies suggesting that differential inflammatory mechanisms may account for differences in metabolic risk factors associated with increasing BMI. Future research studies could benefit from examining longitudinal changes in methylation associated with change in metabolic health status to determine the direction of effect and single cell epigenomic signatures of obesity and metabolic health to examine how individual cell profiles influence this relationship. 
Table 3 Significant CpG sites associated with incident coronary heart disease $(\mathrm{CHD})$ in the Women's Health Initiative (WHI) over 25 years

\begin{tabular}{llll}
\hline CpG site & Hazard ratio & 95\% Cl & P value \\
\hline cg02851049 & 0.90 & $(0.81,0.99)$ & 0.030 \\
cg20210586 & 1.09 & $(1.00,1.19)$ & 0.046 \\
cg16461485 & 0.94 & $(0.89,0.99)$ & 0.031 \\
cg16461485 & 0.93 & $(0.88,0.99)$ & 0.023 \\
cg16543390 & 1.06 & $(1.01,1.11)$ & 0.028 \\
\hline
\end{tabular}

Cox proportional hazard model examining the association between incident $\mathrm{CHD}$ and $\beta$ value of the $22 \mathrm{CpG}$ sites in discovery analysis. Models adjusted for age, race/ethnicity, smoking status, case-control status (BAA23 and AS311), DNA methylation array, row, and cell composition in reduced model ${ }^{\mathrm{a}}$ and reduced model covariates and physical activity and diet in the full model ${ }^{b}$

\section{Methods}

\section{Study population}

Two cohorts were used in the discovery phase: the WHI and the ARIC. Data from three WHI ancillary studies were included: EMPC, aka AS315, the BAA23, and AS311. EMPC assessed epigenetic mechanisms underlying associations between ambient particulate matter air pollution and cardiovascular disease within the WHI Clinical Trials (CT, $n=2200$ ). BAA23 was a case-control study assessing predictors of coronary heart disease (CHD) within the WHI CT $(n=1664)$ and observational study (OS, $n=442$ ), where cases were identified using eight biomarkers of CHD. AS311 is a matched case-control study of bladder cancer among women within the WHI CT $(n=405)$ and OS $(n=455)$ [38].

ARIC included data from two ancillary studies of AA and EA. ARIC is an ongoing prospective cohort study investigating the etiology of CHD in four US communities: Forsyth County, NC; Jackson, MS; Minneapolis, MN; Washington County; MD. Participants were aged 45-64 and followed up in each community over 30 years with 7 study visits $[39,40]$. DNAm was measured in 2879 AA and 1100 EA participants from ARIC in visit 2 (1990-1992) or visit 3 (1993-1995).

The replication cohort derived from the MESA study. MESA is a longitudinal, population cohort study designed to examine risk factors for and the progression of CHD. Participants aged 45-84 years without clinically apparent CHD were recruited between July 2000 and August 2002 from six regions in the USA: Winston-Salem, NC; Northern New York, NY; Baltimore, MD; St. Paul, MN; Chicago, IL; and Los Angeles, CA. DNAm was derived from peripheral blood mononuclear cell samples at Exam 1 or Exam 5 in a random sample of 1200 non-Hispanic
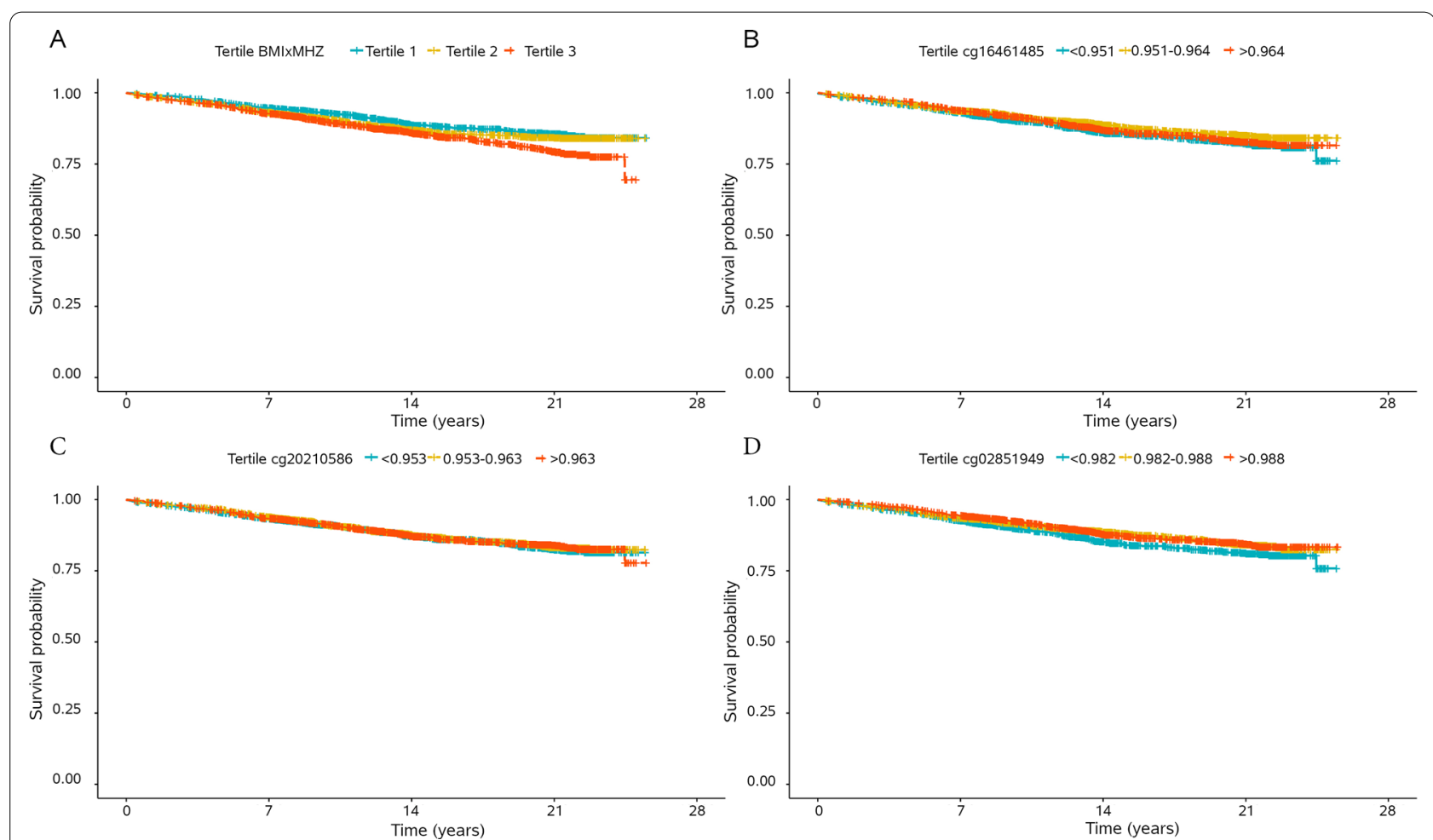

Fig. 4 Probability of incident CHD by tertile of the interaction between body mass index (BMI) and metabolic health Z score (BMI $\times$ MHZ) (A) and CpG site methylation of cg16461485 (B), cg20210586 (C), and cg02851049 (D) over 25 years in the Women's Health Initiative (WHI) 
Table 4 Adult treatment panel (ATP) III clinical identification of metabolic syndrome

\begin{tabular}{ll}
\hline Clinical measure & Defining level \\
\hline Waist circumference & $\geq 102 \mathrm{~cm}$ in men or $\geq 88 \mathrm{~cm}$ in women \\
Triglycerides & $\geq 150 \mathrm{mg} / \mathrm{dL}$ or drug treatment for elevated triglycerides \\
High density lipoprotein (HDL) & $<40 \mathrm{mg} / \mathrm{dL}$ in $\mathrm{men} \mathrm{or}<50 \mathrm{mg} / \mathrm{dL}$ in women or drug treatment for \\
Blood pressure & reduced HDL \\
Glucose & $\geq 130 / 85 \mathrm{mmHG}$ or drug treatment for hypertension \\
\hline
\end{tabular}

white, AA, Hispanic, and Chinese American participants $[41,42]$.

\section{Measurements}

In WHI, weight, height, waist circumference, and blood pressure (BP) were measured at the physical exam. In ARIC, these measurements were taken at Visit 2 or 3. BMI was calculated as weight $(\mathrm{kg}) /$ height $(\mathrm{m})^{2}$. Waist circumference was measured to the nearest $0.5 \mathrm{~cm}$. Systolic/diastolic BP was measured twice and three times in WHI and ARIC, respectively, with the average of the two (WHI) or last two (ARIC) measurements used. Biochemical measurements were analyzed in blood samples collected after a 12-h fast. These include triglycerides (TG), HDL, and fasting glucose.

\section{Metabolic health exposures}

Metabolic health was examined in two ways, dichotomously and continuously. Metabolic risk was dichotomously defined by the presence of three or more components of metabolic syndrome using the Adult Treatment Panel III (ATP III) criteria (Table 4). Thus, MUO and MHO referred to the presence of three or more and less than three components, respectively. Metabolic health was also examined continuously as a $Z$ score of the clinical measures used in the ATP III criteria. For each metabolic parameter, for example TG, the $Z$ score for TG was created by (TG - mean TG)/standard deviation (TG) of the population. Then all the clinical parameter $Z$ scores were pooled to define a MHZ. For HDL, the inverse of HDL was used as a higher MHZ is indicative of poorer health. We examined the HDL variable for normality (Additional file 1: Figure S14-S15). We examined BMI continuously. Individuals were excluded if metabolic health parameters and DNAm were not measured within the same year.

\section{Covariates}

Age, race/ethnicity (White, AA, Hispanic/Latino, Asian, American Indian, other in WHI and EA and AA in ARIC), and smoking status (current/former or never) were self-reported. Physical activity was measured by the
Baecke questionnaire in ARIC [43] and a self-administered questionnaire in WHI [44] and expressed as total energy expended from light, moderate, or vigorous intensity recreational physical activity which includes walking, mild, moderate, and strenuous physical activity in $\mathrm{kcal} /$ week/kg (MET-hours/week).

\section{DNA methylation}

In the all cohorts, DNA was extracted from peripheral blood leucocytes collected at visit-specific fasting blood draws [45]. In the WHI and ARIC cohorts, DNAm was measured using the Illumina HM450K Infinium Methylation BeadChip. In the MESA cohort, DNAm was measured via the Illumina MethylationEPIC BeadChip array. DNAm was estimated as the proportion of methylated beads relative to combined unmethylated and methylated beads for a specific $\mathrm{CpG}$ site defined as the $\beta$ value (ranging from 0 [unmethylated] to 1 [methylated]). All methylation data were normalized using beta-mixture quantile normalization [46]. Technical covariates included chip and row to adjust for batch effects and cell composition, which was estimated using the reference-based Houseman method [34]. Additional quality control procedures for each of the studies has been included in the Additional file 1: Methods. After quality control, 428,278 probes remained in all cohorts and were examined.

\section{Statistical analysis}

We used R (https://www.r-project.org/) for all analyses. We calculated means and standard deviations or counts and proportions for study population characteristics. In the EWAS, all models were stratified by cohort (EMPC, BAA23, AS311 in WHI) or race (AA and EA in ARIC) and pooled using inverse-variance weighted fixed effect meta-analysis. BMI was examined continuously. To examine the differential impact of metabolic health status on BMI, linear regression models were used regressing the methylation $\beta$ value on the interaction term for BMI and metabolic health status, adjusting for each higher-level variable (BMI and metabolic health) and covariates. We conducted two EWAS with metabolic health status defined dichotomously (BMIxMH) 
and continuously (BMIxMHZ). Covariates in all models included cell composition, the top three principal components of genetic relatedness, race/ethnicity (WHI), sex (ARIC), smoking status, row, and age. WHI study-specific covariates included trial study and randomization arm (EMPC, BAA23, AS311) and case-control status (BAA23, AS311). To adjust for batch effects, the DNAm array was included as a random effect for each BeadChip in our model. Significant CpG sites were identified by the interaction $p$ value at a FDR $q$ value $<0.05$. We examined the correlation between BMI and MHZ to test for collinearity (Additional file 1: Figure S16). These variables were not highly correlated.

Results identified in the discovery cohorts were replicated in the MESA cohort using linear regression models as previously described. Significant CpG sites were examined using the same linear regression model as above examining BMI $\times$ MHZ. Models were adjusted for DNAm array number and row location, cell composition, principal components of genetic relatedness, race/ethnicity, age, sex, alcohol consumption, and smoking. Significant replication was defined at $p<0.05$ and a consistent direction of effect.

\section{Outcomes analyses}

In significant sites identified through EWAS, DNAm at CpG sites was examined as a predictor of incident CHD in the WHI. CHD was defined by incident myocardial infarction or CHD death. Acute, hospitalized myocardial infarction was identified in medical records on the basis of cardiac pain, electrocardiogram, and biomarker data, and then physician-adjudicated. Further details regarding the review, classification, and adjudication of CHD in WHI have been described [47].

Multivariate Cox proportional hazard ratios were used to examine whether significant sites identified through EWAS (exposure) were associated with incident CHD in WHI. Individuals with a history of (or incident) myocardial infarction or coronary revascularization (angioplasty; stent; bypass) before measurement of DNAm were excluded. Covariates included age, race/ethnicity, smoking status, case-control status (BAA23 and AS311), DNAm array, row, and cell composition in the reduced model. In the full model, we adjusted for the covariates in the reduced model as well as physical activity and diet quality. Diet quality was measured using the Alternative Healthy Eating Index-2010 score [48] derived from food frequency questionnaires in the WHI. Significant sites were defined by $p<0.05$.

\section{Gene expression}

To elucidate the potential functional implications of the identified $\mathrm{CpG}$ sites, we examined gene expression information using previously published significant gene expression quantitative trait methylation loci (eQTMs) summary statistics in blood from MESA and the GTP [49]. We examined the summary statistics for the four CpG sites identified in validation and in secondary CHD analyses. This population from MESA had minimal overlap with the MESA population examined in replication analyses.

\section{Sensitivity analyses}

As metabolic health status is constructed from several metabolic parameters, differences in methylation may be driven by individual metabolic parameters. To assess the degree that individual metabolic parameters influence methylation at significant sites, we reanalyzed associations between $\mathrm{BMI} \times \mathrm{MHZ}$ status and methylation excluding individual metabolic parameter in the MHZ score and compared the effects to the original estimates obtained through EWAS. For the significant sites, we also examined changes in effect size when adjusting for lipid, hypertension and glycemic medication use. We additionally repeated the primary EWAS analysis adjusting for physical activity. We additionally examined the four sites identified in replication and secondary analyses for normality and heteroskedasticity by examining the QQ plots and residual plots from the discovery analysis.

\begin{abstract}
Abbreviations
BMI: Body mass index; DNAm: DNA methylation; CpG: Cytosine-phosphateguanine; WHI: Women's Health Initiative; ARIC: Atherosclerosis Risk in Communities; MHZ: Metabolic health Z score; ATP: Adult treatment panel; BMI $\times$ MHZ: Interaction between body mass index and metabolic health $Z$ score; FDR: False discovery rate; CHD: Coronary heart disease; $\mathrm{MHO}$ : Metabolically healthy obesity; MUO: Metabolically unhealthy obesity; RR: Risk ratio; EMPC: Epigenetic Mechanisms of Particulate Matter-Mediated Cardiovascular Disease; BAA23: Integrative Genomics for Risk of Coronary Heart Disease and Related Phenotypes in WHI cohort; AS311: Bladder Cancer and Leukocyte Methylation; CT: Clinical trial; OS: Observational study; AA: African American; EA: European American; MESA: Multi-ethnic Study of Atherosclerosis; BP: Blood pressure; TG: Triglycerides; HDL: High-density lipoprotein cholesterol; EWAS: Epigenomewide association study; eQTM: Expression quantitative trait methylation loci; GTP: Grady Trauma Project; HR: Hazard ratio; TNF: Tumor necrosis factor; TACl: Transmembrane activator and CAML interactor; CRP: C-reactive protein; IL-6: Interleukin 6.
\end{abstract}

\section{Supplementary Information}

The online version contains supplementary material available at https://doi. org/10.1186/s13148-021-01194-3.

Additional file 1. Supplemental Figures 1-16. Supplemental Tables 1-6.

\section{Acknowledgements}

The authors would like to acknowledge and thank all participants from the WHI, ARIC, and MESA.

Authors' contributions

WLD, KMVN , and KC conceived of the study. The methodology was developed by WLD, KMVN, ADS, AS, and LRS. The data for WHI were curated by EAS, YL, 
SH, TLA, PB, and KJ. The data for ARIC were curated by ED, WG, and AEJ. The data for MESA were curated by XG, JR, SSR, LL, JD, and DVDB. All analyses were completed by WLD, SN, and JY. The manuscript was written by WLD. Editorial and content expertise was provided by all authors. All authors read and approved the final manuscript.

\section{Funding}

The WHI program is funded by the National Heart, Lung, and Blood Institute, National Institutes of Health, US Department of Health and Human Services through contracts HHSN268201600018C, HHSN268201600001C, HHSN268201600002C, HHSN268201600003C, and HHSN268201600004C. The Atherosclerosis Risk in Communities study has been funded in whole or in part with Federal funds from the National Heart, Lung, and Blood Institute (NHLBI), National Institutes of Health, Department of Health and Human Services (contract numbers HHSN268201700001I, HHSN268201700002I, HHSN268201700003I, HHSN268201700004I, and HHSN268201700005I). The authors thank the staff and participants of the ARIC study for their important contributions. Funding was also supported by 5RC2HL102419 and R01NS087541. MESA TOPMed Methylation data for the Trans-Omics in Precision Medicine (TOPMed) program was supported by the NHLBI. MESA TOPMed Methylation data for "Genome-wide methylation for NHLBI TOPMed: Multi-Ethnic Study of Atherosclerosis (MESA)" (phs001416.v1.p1) were performed at Keck Molecular Genomics Core Facility (HHSN268201600034I). Centralized read mapping and genotype calling, along with variant quality metrics and filtering were provided by the TOPMed Informatics Research Center (3R01HL-117626-02S1, contract HHSN268201800002I). Phenotype harmonization, data management, sample-identity QC, and general study coordination were provided by the TOPMed Data Coordinating Center (R01HL-120393; U01HL-120393; contract HHSN268201800001I). We gratefully acknowledge the studies and participants who provided biological samples and data for TOPMed. WLD was supported in part by the Nalini and Ravi Saligram Scholarship.

\section{Availability of data and materials}

The data for all studies are publicly available and more information can be found at the individual cohort websites: WHI (www.whi.org), ARIC (https:// sites.cscc.unc.edu/aric/desc), and MESA (www.mesa-nhlbi.org).

\section{Declarations}

\section{Ethics approval and consent to participate}

Ethics approval was obtained for all the studies, and all participants provided consent to participate in individual studies. More information can be found for the cohorts at the following websites: WHI (www.whi.org), ARIC (https://sites. cscc.unc.edu/aric/desc), and MESA (www.mesa-nhlbi.org).

\section{Consent for publication}

Not applicable.

\section{Competing interests}

The authors declare they have no competing interests.

\footnotetext{
Author details

${ }^{1}$ Nutrition and Health Sciences Program, Laney Graduate School, Emory University, 1518 Clifton Rd, Atlanta, GA 30322, USA. ${ }^{2}$ Herbert Wertheim School of Public Health and Human Longevity Science, University of California, San Diego, CA, USA. ${ }^{3}$ Department of Pediatrics, The Institute for Translational Genomics and Population Sciences, The Lundquist Institute for Biomedical Innovation at Harbor-UCLA Medical Center, Torrance, CA, USA. ${ }^{4}$ Departments of Epidemiology and Medicine, University of North Carolina, Chapel Hill, NC, USA. ${ }^{5}$ Division of Epidemiology and Community Health, School of Public Health, University of Minnesota, Minneapolis, MN, USA. ${ }^{6}$ Center for Public Health Genomics, University of Virginia, Charlottesville, VA, USA. ${ }^{7}$ Division of Biomedical Informatics \& Personalized Medicine, School of Medicine, Colorado University Anschutz Medical Campus, Aurora, CO, USA. ${ }^{8}$ Gerontology and Geriatric Medicine, School of Medicine, Wake Forest, Winston-Salem, NC, USA. ${ }^{9}$ Department of Population and Public Health Sciences, University of Southern California, Los Angeles, CA, USA. ${ }^{10}$ Duke Molecular Physiology Institute, Duke University, Durham, NC, USA. ${ }^{11}$ Center for Biomedical and Translational Informatics, Geisinger, Wilkes-Barre, PA, USA. ${ }^{2}$ Division
}

of Biostatistics, School of Public Health, University of Minnesota, Minneapolis, MN, USA. ${ }^{13}$ Department of Human Genetics, University of California, Los Angeles, Los Angeles, CA, USA. ${ }^{14}$ Department of Medicine, Stanford University, Stanford, CA, USA. ${ }^{15}$ Cancer Control Research, BC Cancer, Vancouver, BC, Canada. ${ }^{16}$ Department of Epidemiology, University of Washington, Seattle, WA, USA. ${ }^{17}$ College of Medicine, University of Arizona Cancer Center, Tucson, AZ, USA. ${ }^{18}$ Hubert Department of Global Health, Rollins School of Public Health, Emory University, Atlanta, GA, USA. ${ }^{19}$ Department of Gynecology and Obstetrics, School of Medicine, Emory University, Atlanta, GA, USA. ${ }^{20}$ Department of Human Genetics, Emory University, Atlanta, GA, USA.

Received: 19 August 2021 Accepted: 1 November 2021

Published online: 22 December 2021

\section{References}

1. Hales CM, Fryar CD, Ogden CL. Prevalence of obesity among adults and youth: United States, 2015-2016. 2017.

2. Winter JE, MacInnis RJ, Wattanapenpaiboon N, Nowson CA. BMI and all-cause mortality in older adults: a meta-analysis. Am J Clin Nutr. 2014:99:875-90.

3. Evans EM, Rowe DA, Racette SB, Ross KM, McAuley E. Is the current BMI obesity classification appropriate for black and white postmenopausal women? Int J Obes. 2006;30:837-43.

4. Flegal KM, Kit BK, Orpana H, Graubard BI. Association of all-cause mortality with overweight and obesity using standard body mass index categories: a systematic review and meta-analysis. JAMA. 2013;309:71-82.

5. Xu H, Cupples LA, Stokes A, Liu C-T. Association of obesity with mortality over 24 years of weight history: findings from the Framingham Heart Study. JAMA Netw Open. 2018;1:e184587-e184587.

6. Mongraw-Chaffin M, Foster MC, Kalyani RR, Vaidya D, Burke GL, Woodward M, Anderson CAM. Obesity severity and duration are associated with incident metabolic syndrome: evidence against metabolically healthy obesity from the multi-ethnic study of atherosclerosis. J Clin Endocrinol Metab. 2016;101:4117-24.

7. Mongraw-Chaffin M, Foster MC, Anderson CAM, Burke GL, Haq N, Kalyani RR, Ouyang P, Sibley CT, Tracy R, Woodward M, Vaidya D. Metabolically healthy obesity, transition to metabolic syndrome, and cardiovascular risk. J Am Coll Cardiol. 2018;71:1857-65.

8. Stefan N, Häring HU, Schulze MB. Metabolically healthy obesity: the low-hanging fruit in obesity treatment? Lancet Diabetes Endocrinol. 2018;6:249-58.

9. Hamer M, Stamatakis E. Metabolically healthy obesity and risk of allcause and cardiovascular disease mortality. J Clin Endocrinol Metab. 2012;97:2482-8.

10. Guo F, Garvey WT. Cardiometabolic disease risk in metabolically healthy and unhealthy obesity: Stability of metabolic health status in adults. Obesity (Silver Spring). 2016;24:516-25.

11. Roberson LL, Aneni EC, Maziak W, Agatston A, Feldman T, Rouseff M, Tran T, Blaha MJ, Santos RD, Sposito A, Al-Mallah MH, Blankstein R, Budoff MJ, Nasir K. Beyond BMI: The "Metabolically healthy obese" phenotype \& its association with clinical/subclinical cardiovascular disease and all-cause mortality - a systematic review. BMC Public Health. 2014;14:14.

12. Eckel N, Meidtner K, Kalle-Uhlmann T, Stefan N, Schulze MB. Metabolically healthy obesity and cardiovascular events: a systematic review and metaanalysis. Eur J Prev Cardiol. 2015;23:956-66.

13. Petronis A. Epigenetics as a unifying principle in the aetiology of complex traits and diseases. Nature. 2010;465:721-7.

14. Wang X, Zhu H, Snieder H, Su S, Munn D, Harshfield G, Maria BL, Dong Y, Treiber F, Gutin B, Shi H. Obesity related methylation changes in DNA of peripheral blood leukocytes. BMC Med. 2010;8:87.

15. Dick KJ, Nelson CP, Tsaprouni L, Sandling JK, Aïssi D, Wahl S, Meduri E, Morange P-E, Gagnon F, Grallert H, Waldenberger M, Peters A, Erdmann J, Hengstenberg C, Cambien F, Goodall AH, Ouwehand WH, Schunkert H, Thompson JR, Spector TD, Gieger C, Trégouët D-A, Deloukas P, Samani NJ. DNA methylation and body-mass index: a genome-wide analysis. The Lancet. 2014;383:1990-8.

16. Sayols-Baixeras S, Subirana I, Fernández-Sanlés A, Sentí M, Lluís-Ganella C, Marrugat J, Elosua R. DNA methylation and obesity traits_-an 
epigenome-wide association study: The REGICOR study. Epigenetics. 2017:12:909-16

17. Barres R, Zierath JR. DNA methylation in metabolic disorders. Am J Clin Nutr. 2011;93:897S-900S.

18. Samblas M, Milagro Fl, Martínez A. DNA methylation markers in obesity, metabolic syndrome, and weight loss. Epigenetics. 2019;14:421-44.

19. Braun KVE, Dhana K, de Vries PS, Voortman T, van Meurs JBJ, Uitterlinden AG, Hofman A, Hu FB, Franco OH, Dehghan A, Consortium B. Epigenomewide association study (EWAS) on lipids: the Rotterdam Study. Clin Epigenetics. 2017; 9:15.

20. Dhana K, Braun KVE, Nano J, Voortman T, Demerath EW, Guan W, Fornage $M$, van Meurs JBJ, Uitterlinden AG, Hofman A, Franco OH, Dehghan A. An epigenome-wide association study of obesity-related traits. Am J Epidemiol. 2018;187:1662-9.

21. Walaszczyk E, Luijten M, Spijkerman AMW, Bonder MJ, Lutgers HL, Snieder $\mathrm{H}$, Wolffenbuttel BHR, van Vliet-Ostaptchouk JV. DNA methylation markers associated with type 2 diabetes, fasting glucose and HbA1c levels: a systematic review and replication in a case-control sample of the Lifelines study. Diabetologia. 2018;61:354-68.

22. Wang F, Deeney JT, Denis GV. Brd2 gene disruption causes "metabolically healthy" obesity: epigenetic and chromatin-based mechanisms that uncouple obesity from type 2 diabetes. Vitam Horm. 2013;91:49-75.

23. Mendelson MM, Marioni RE, Joehanes R, Liu C, Hedman ÅK, Aslibekyan S, Demerath EW, Guan W, Zhi D, Yao C, Huan T, Willinger C, Chen B, Courchesne P, Multhaup M, Irvin MR, Cohain A, Schadt EE, Grove ML, Bressler J, North K, Sundström J, Gustafsson S, Shah S, McRae AF, Harris SE, Gibson J, Redmond P, Corley J, Murphy L, Starr JM, Kleinbrink E, Lipovich L, Visscher PM, Wray NR, Krauss RM, Fallin D, Feinberg A, Absher DM, Fornage M, Pankow JS, Lind L, Fox C, Ingelsson E, Arnett DK, Boerwinkle E, Liang L, Levy D, Deary IJ. Association of Body Mass Index with DNA methylation and gene expression in blood cells and relations to cardiometabolic disease: a mendelian randomization approach. PLoS Med. 2017;14:e1002215-e1002215.

24. TRAPPC9 Gene

25. Liang ZS, Cimino I, Yalcin B, Raghupathy N, Vancollie VE, Ibarra-Soria X, Firth HV, Rimmington D, Faroogi IS, Lelliott CJ, Munger SC, O'Rahilly S, Ferguson-Smith AC, Coll AP, Logan DW. Trappc9 deficiency causes parent-of-origin dependent microcephaly and obesity. PLoS Genet. 2020;16:e1008916.

26. Huang RC, Garratt ES, Pan H, Wu Y, Davis EA, Barton SJ, Burdge GC, Godfrey KM, Holbrook JD, Lillycrop KA. Genome-wide methylation analysis identifies differentially methylated $\mathrm{CpG}$ loci associated with severe obesity in childhood. Epigenetics. 2015;10:995-1005.

27. Rzehak P, Covic M, Saffery R, Reischl E, Wahl S, Grote V, Weber M, Xhonneux A, Langhendries J-P, Ferre N, Closa-Monasterolo R, Escribano J, Verduci E, Riva E, Socha P, Gruszfeld D, Koletzko B. DNA-methylation and body composition in preschool children: epigenome-wide-analysis in the European childhood obesity project (CHOP)-Study. Sci Rep. 2017;7:14349.

28. Jones PA. Functions of DNA methylation: islands, start sites, gene bodies and beyond. Nat Rev Genet. 2012;13:484-92.

29. TNFRSF13B Gene.

30. Liu L, Inouye KE, Allman WR, Coleman AS, Siddiqui S, Hotamisligil GS, Akkoyunlu M. TACl-deficient macrophages protect mice against metaflammation and obesity-induced dysregulation of glucose homeostasis. Diabetes. 2018;67:1589-603.

31. Ferrante AW Jr. Obesity-induced inflammation: a metabolic dialogue in the language of inflammation. J Intern Med. 2007;262:408-14.

32. Karelis AD, Faraj M, Bastard JP, Pierre DH, Brochu M, Prud'homme RabasaLhoret DR. The metabolically healthy but obese individual presents a favorable inflammation profile. J Clin Endocrinol Metab. 2005;90:4145-50.

33. Phillips CM, Perry IJ. Does inflammation determine metabolic health status in obese and nonobese adults? J Clin Endocrinol Metab. 2013;98:E1610-9.

34. Houseman EA, Molitor J, Marsit CJ. Reference-free cell mixture adjustments in analysis of DNA methylation data. Bioinformatics (Oxford, England). 2014;30:1431-9.

35. Doumatey AP, Lashley KS, Huang H, Zhou J, Chen G, Amoah A, AgyenimBoateng K, Oli J, Fasanmade O, Adebamowo CA, Adeyemo AA, Rotimi CN. Relationships among obesity, inflammation, and insulin resistance in African Americans and West Africans. Obesity. 2010;18:598-603.
36. Hakim O, Bello O, Ladwa M, Peacock JL, Umpleby AM, Charles-Edwards G, Amiel SA, Goff LM. The link between obesity and inflammatory markers in the development of type 2 diabetes in men of Black African and White European Ethnicity. Nutrients. 2020;12:3796.

37. Power C, Thomas C. Changes in BMl, duration of overweight and obesity, and glucose metabolism: 45 years of follow-up of a birth cohort. Diabetes Care. 2011;34:1986-91.

38. Design of the Women's Health Initiative clinical trial and observational study. The Women's Health Initiative Study Group. Controlled Clin Trials. 1998;19:61-109.

39. Sharrett AR. The Atherosclerosis Risk in Communities (ARIC) Study: introduction and objectives of the hemostasis component. Ann Epidemiol. 1992:2:467-9.

40. Investigators TA. The atherosclerosis risk in communities (ARIC) study: design and objectives. Am J Epidemiol. 1989;129:687-702.

41. Bild DE, Bluemke DA, Burke GL, Detrano R, Diez Roux AV, Folsom AR, Greenland P, Jacob DR Jr, Kronmal R, Liu K, Nelson JC, O'Leary D, Saad MF, Shea S, Szklo M, Tracy RP. Multi-ethnic study of atherosclerosis: objectives and design. Am J Epidemiol. 2002;156:871-81.

42. Bild DE, Bluemke DA, Burke GL, Detrano R, DiezRoux AV, Folsom AR, Greenland P, Jacobs DR, Kronmal R, Liu K, Nelson JC, O'Leary D, Saad MF, Shea S, Szklo M, Tracy RP. Multi-ethnic study of atherosclerosis: objectives and design. Am J Epidemiol. 2002;156:871-81.

43. Richardson MT, Ainsworth BE, Wu H-C, Jacobs DR, Leon AS. Ability of the Atherosclerosis Risk in Communities (ARIC)/Baecke Questionnaire to assess leisure-time physical activity. Int J Epidemiol. 1995;24:685-93.

44. Meyer A-M, Evenson KR, Morimoto L, Siscovick D, White E. Test-retest reliability of the Women's Health Initiative physical activity questionnaire. Med Sci Sports Exerc. 2009:41:530-8.

45. Gondalia R, Baldassari A, Holliday KM, Justice AE, Méndez-Giráldez R, Stewart JD, Liao D, Yanosky JD, Brennan KJM, Engel SM, Jordahl KM, Kennedy E, Ward-Caviness CK, Wolf K, Waldenberger M, Cyrys J, Peters A, Bhatti P, Horvath S, Assimes TL, Pankow JS, Demerath EW, Guan W, Fornage M, Bressler J, North KE, Conneely KN, LiY, Hou L, Baccarelli AA, Whitsel EA. Methylome-wide association study provides evidence of particulate matter air pollution-associated DNA methylation. Environ Int. 2019;2019:104723.

46. Teschendorff AE, Marabita F, Lechner M, Bartlett T, Tegner J, GomezCabrero D, Beck S. A beta-mixture quantile normalization method for correcting probe design bias in Illumina Infinium 450 k DNA methylation data. Bioinformatics (Oxford, England). 2013;29:189-96.

47. Curb JD, MCTiernan A, Heckbert SR, Kooperberg C, Stanford J, Nevitt M, Johnson KC, Proulx-Burns L, Pastore L, Criqui M, Daugherty S. Outcomes ascertainment and adjudication methods in the Women's Health Initiative. Ann Epidemiol. 2003;13:S122-8.

48. Chiuve SE, Fung TT, Rimm EB, Hu FB, McCullough ML, Wang M, Stampfer $\mathrm{MJ}$, Willett WC. Alternative dietary indices both strongly predict risk of chronic disease. J Nutr. 2012;142:1009-18.

49. Kennedy EM, Goehring GN, Nichols MH, Robins C, Mehta D, Klengel T, Eskin E, Smith AK, Conneely KN. An integrated-omics analysis of the epigenetic landscape of gene expression in human blood cells. BMC Genomics. 2018;19:476.

\section{Publisher's Note}

Springer Nature remains neutral with regard to jurisdictional claims in published maps and institutional affiliations. 